\title{
Spectrum of epilepsy in Neurocysticercosis
}

\author{
Anoop Kumar ${ }^{1}$, Singh R.R ${ }^{2}$, Verma $V K^{3}$, Uraiya $D^{4}$, Tripathi $N^{5}$. \\ ${ }^{1,3,4,5}$ Assistant Professor, ${ }^{2}$ Associate Professor; all authors are attached with Department of Medicine, Hind Institute of \\ Medical Sciences, Safedabad, Barabanki, U.P, India.
}

Address for Correspondence: Anoop Kumar, Assistant Professor, Department of Medicine, Hind Institute of Medical Sciences, Safedabad, Barabanki, U.P. Email: kanoopdr@gmail.com

\begin{abstract}
Introduction: Neurocysticercosis (NCC) is one of the most common parasitic cause of neurological disease in developing countries. NCC is the infestation of the central nervous system with the larvae of pork tapeworm, Taenia solium. It is endemic in South Asia, Africa, and Latin America. Due to increasing international travel and immigration, NCC is no more a health issue limited to the developing countries but also to the rest of world. Material and methods: A total of 70 patients of seizures presenting with ring enhancing lesion in CT scan of brain suggestive of neurocysticercosis, attending outpatient department or admitted in wards of Medicine Department of S.R.N. Hospital. A detailed seizure history as well as neurological examination was done according to the working proforma. Results: Maximum number of patients $34(48.57 \%)$ were presented with simple partial seizures with secondary generalization. Generalized tonic-clonic seizure was present in 22 patient $(31.43 \%)$ patients. Simple partial seizure without secondary generalization was presented in 12 patients $(17.14 \%)$. Two patients $(2.86 \%)$ were presented with complex partial seizure. Conclusion: Neurocysticercosis is more common in young, rural population and in lower socioeconomic class. Vegetarians were significantly more affected than non-vegetarians which suggest other mode of transmission. By combining hygiene education and better sanitation, we will interrupt or reduce the cycle of direct person-to-person transmission. Thus, probably we will succeed to reduce the burden of disease from the society.
\end{abstract}

Keywords: Dietary habits, Epilepsy, Neurocysticercosis, Seizures.

\section{Introduction}

Neurocysticercosis (NCC) is one of the most common parasitic cause of neurological disease in developing countries. NCC is the infestation of the central nervous system with the larvae of pork tapeworm, Taenia solium. It is endemic in South Asia, Africa, Latin America [1]. Due to increasing international travel and immigration, NCC is no more a health issue limited to the developing countries but also to the rest of world [2]. It has been estimated that 50 million people are infected with the Taenia/cysticercosis complex in the world and that 50,000 die each year [3].

The clinical presentation of the neurocysticercosis is diverse, depends upon the number, location, size, viability or stage of degeneration of cysts and intensity of the immune response of the host to the parasites [4].

Manuscript received $10^{\text {th }}$ July 2016

Reviewed: $24^{\text {th }}$ July 2016

Author Corrected: $5^{\text {th }}$ August 2016

Accepted for Publication $17^{\text {th }}$ August 2016
Seizure (particularly late onset seizure) are the most common presentation (50-80\% of cases) followed by headache $(40 \%)$ visual changes $(20 \%)$ confusion $(15 \%)$, and less frequently cranial nerve palsies or other focal neurological deficits $[5,6]$.

Complex neurological and neurosurgical syndrome have been described as a result of infestation with NCC [7] including a number of uncommon clinical presentations such as stroke [8], mid brain syndrome [9] and Weber syndrome [10]. Neurocysticercosis also presented with psychiatric symptoms or syndromes including mutism [11], mood and psychotic symptoms [12].

Thus, this study was conducted in Medicine Department, M .L. N. Medical College, Allahabad to evaluate spectrum of epilepsy in neurocysticercosis patient. 


\section{Material and Methods}

\section{A. Inclusion Criteria:}

All patients of seizures presenting with ring enhancing lesion in CT scan of brain suggestive of neurocysticercosis, (according to the criteria given by Del Bruto, 2001) [13] including outpatient department or admitted patients in wards of Medicine Department of S.R.N. Hospital, Allahabad. Classification of seizure based on the International classification of epileptic seizure given by International league against of epilepsy [14].

\section{B. Exclusion Criteria :}

a. Patient with primary seizure disorder. b. Patient with history of seizure disorder due to other cause like tuberculoma, space occupying lesions, cerebrovascular accident etc.

Methodology- A detailed seizure history as well as neurological examination was done according to the working proforma. Classification of seizure based on the classification given by International league against epilepsy and diagnosis of neurocyscticercosis based on the criteria given by Del Bruto, (2001) [13]. The relevant investigation like electro-encephalography and computed axial tomography were also done. Besides these routine blood and urine investigation, X-ray chest $\mathrm{PA}$ view, CSF examination was done.

\section{Results}

Age of neurocysticercosis (NCC) patients $(n=70)$ varied from 6 years to 80 years. Mean age of presentation was 23.18 \pm 6.12 . Mean age of presentation of male $(n=47)$ was $24.10 \pm 4.00$ (CI 95\%) while for female ( $n=23)$ was $21.30 \pm 7.71$ (CI 95\%). Most of the patients, $81.43 \%(n=57)$ were less than 30 years of age i.e. in the first three decades. Male and female ratio was 2.04:1.

Out of 70 patients of neurocysticercosis 3 patients (4.29\%) belonged to upper class, 25 patients (35.71\%) belonged to middle class while 42 patients $(60 \%)$ belonged to lower class. Out of 70 patients of neurocysticercosis, $65.71 \%(n=46)$ were of rural population and $34.29 \%(n=24)$ were urban.

Out of 47 male patients of neurocysticercosis, $47.14 \%(n=33)$ were of rural origin and $20 \%(n=14)$ were or urban origin. Out of 23 female patients of neurocysticercosis $18.57 \%(n=13)$ were of rural origin and $14.29 \%(n=10)$ were of urban origin.

Out of 70 patients, $37.14 \%(n=26)$ were non-vegetarian and $62.86 \%(n=44)$ were vegetarians. $25.71 \%(n=18)$ male were non-vegetarians while $41.43 \%(n=29)$ were vegetarian.

Table-1: Distribution of patients according to age at onset of seizures due to NCC

\begin{tabular}{|c|c|c|c|c|c|c|}
\hline \multirow[t]{2}{*}{ Age Group(in year) } & \multicolumn{2}{|c|}{ Male } & \multicolumn{2}{|c|}{ Female } & \multicolumn{2}{|c|}{ Total } \\
\hline & $\mathbf{n}$ & $\%$ & $\mathbf{n}$ & $\%$ & $\mathbf{n}$ & $\%$ \\
\hline $1-10$ & 2 & 2.86 & 7 & 10 & 9 & 12.86 \\
\hline $11-20$ & 24 & 34.28 & 8 & 11.43 & 32 & 45.71 \\
\hline $21-30$ & 12 & 17.15 & 4 & 5.71 & 16 & 22.86 \\
\hline $31-40$ & 3 & 4.28 & 1 & 1.43 & 4 & 5.71 \\
\hline $41-50$ & 5 & 7.14 & 2 & 2.86 & 7 & 10 \\
\hline $51-60$ & 0 & 0 & 0 & 0 & 0 & 0 \\
\hline Above 60 & 1 & 1.43 & 1 & 1.43 & 2 & 2.86 \\
\hline Total & 47 & 67.14 & 23 & 32.86 & 70 & 100 \\
\hline
\end{tabular}

From above table it is evident that $12.86 \%(n=9)$ patients presented with seizure in first decade of life, $45.71 \%(n=32)$ in second decade, $22.86 \%(\mathrm{n}=16)$ in third decade, and $5.71 \%(\mathrm{n}=4)$ in fourth decade of life. Maximum incidence, $42.71 \%$ $(n=32)$ was found in age group of 11-20 years. 
Table-2: Distribution of patients according to site of beginning of seizures.

\begin{tabular}{|c|c|c|c|c|c|c|}
\hline \multirow{2}{*}{ Site of origin } & \multicolumn{2}{|c|}{ Male } & \multicolumn{2}{|c|}{ Female } & \multicolumn{2}{|c|}{ Total } \\
\hline & No. & $\%$ & No. & $\%$ & No. & $\%$ \\
\hline Upper limb & 35 & 50 & 15 & 21.43 & 50 & 71.43 \\
\hline Face & 4 & 5.71 & 3 & 4.29 & 7 & 10.00 \\
\hline Lower limb & 8 & 11.43 & 5 & 7.14 & 13 & 18.57 \\
\hline Total & 47 & 67.14 & 23 & 32.86 & 70 & 100 \\
\hline
\end{tabular}

From the above table it is clear that majority of patients $71.43 \%(\mathrm{n}=50)$ seizures were began from upper limb, followed by lower limb, $18.57 \%(n=3)$.

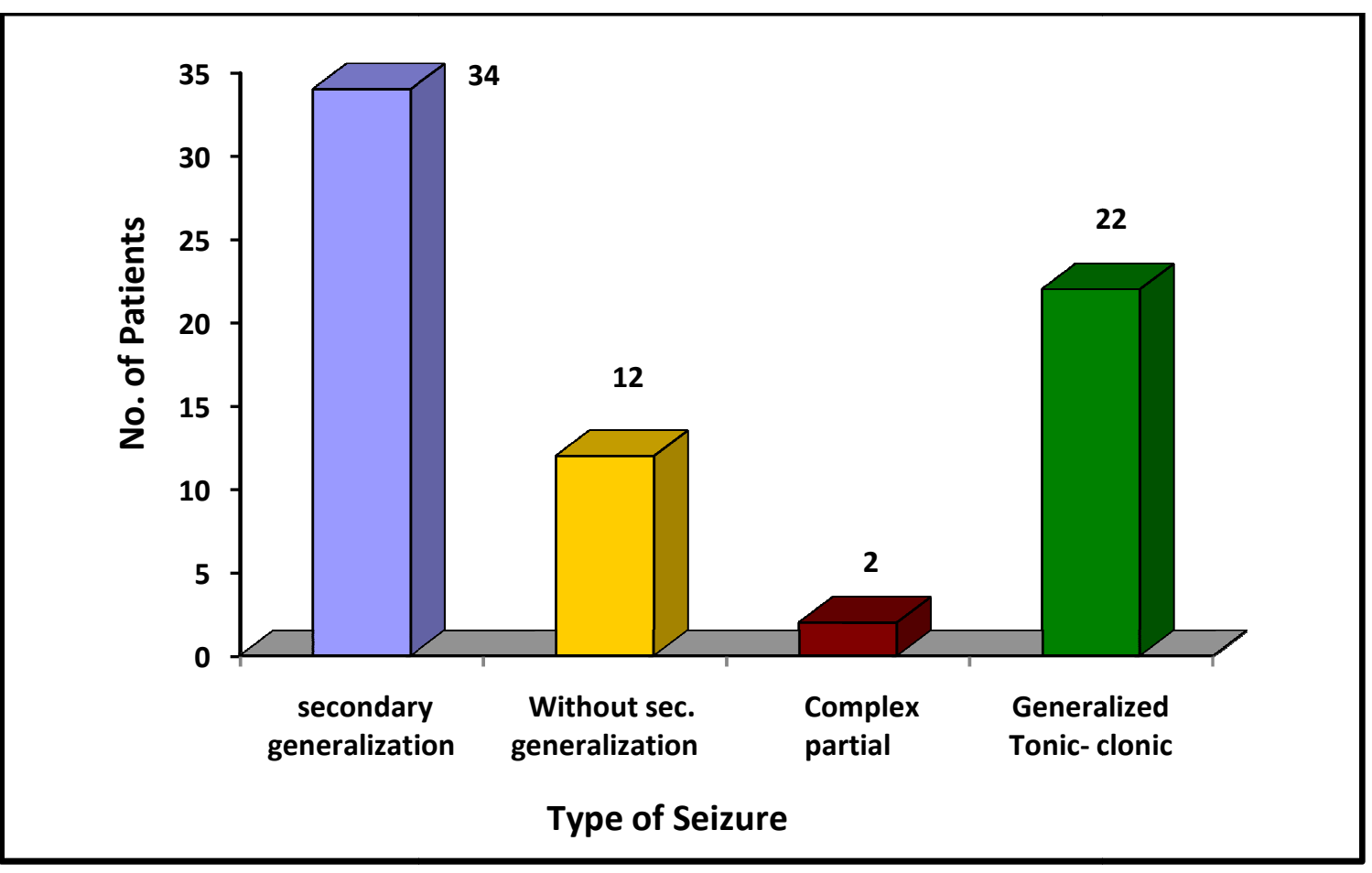

Figure-1: Distribution of patients according to type of seizures.

From the above figure it is evident that maximum number of patients 34 (48.57\%) were presented with simple partial with secondary generalization. Generalized tonic-clonic seizure was present in 22 patient (31.43\%) patients. Simple partial seizure without secondary generalization was presented in 12 patients $(17.14 \%)$. Two patients $(2.86 \%)$ were presented with complex partial seizure.

Table- 3: Distribution of patients according to neurological examination

\begin{tabular}{|c|c|c|}
\hline Findings & Patients & Percentage \\
\hline Normal & 60 & 11.43 \\
\hline Focal neurological deficit & 8 & 10 \\
\hline (a) Monoparesis & 7 & 1.43 \\
\hline (b) Hemiparesis & 1 & 2.86 \\
\hline Papilloedema & 2 & $\mathbf{1 0 0}$ \\
\hline Total & $\mathbf{7 0}$ & \\
\hline
\end{tabular}




\section{Discussion}

Age and sex: In the present study, maximum number of patients $45.71 \%(\mathrm{n}=32)$ is encountered in the age group of $11-20$ years followed by $22.86 \%(n=16)$ in $21-30 y r s$ age group. Majority of the patients $81.43 \%(n=57)$ were below 30 years of age. The mean age was $23.18 \mathrm{yr} \pm$ $6.71 y r s$. These results are closely resembled with studies of RS Wadia et al (1987); Pazzaglia et al (1981) in which the patients below age of 20 years were $42.4 \%$ and $50 \%$ respectively. There were 47 males $(67.47 \%)$ and 23 females $(32.86 \%)$. The male: female ratio is 2.04:1 which closely resemble with the study conducted by $\mathrm{OH}$ Del Brutto et al (1988) [15] in which they reported male: female ratio of about 2:1.

Rural urban, Socio-economic class and dietary habits: In the present study, 65.71\% $(n=46)$ patients were from rural origin and $34.29 \%(n=24)$ were from urban origin. $60.0 \% \quad(n=42)$ patients in this study belonged to lower socioeconomic class.

Thus, it is evident that in present study more than $60 \%$ of the patients are from rural origin and belong to lower socioeconomic classes which are similar to the other study [16], where $70 \%$ patients are from rural origin and belonged to lower socioeconomic classes. In the Verma [17] series, $63.5 \%$ patients are from rural origin and lower socioeconomic classes. In the present study, $37.14 \%(n=26)$ were non-vegetarian and $62.86 \%(n=44)$ were vegetarian. Singh et al. (2001) [18] reported that $59 \%$ of the cases from Uttaranchal were vegetarian and only $17.6 \%$ of them were pork eaters.

Age at onset of seizure: In this study, age at onset of seizure was found $11-20$ years group in $45.71 \%(n=32)$ cases, followed $21-30$ years in $22.86 \%(n=16)$ cases and $1-10$ years in $12.86 \%(n=9)$ cases. These results are closely in resemblance with the studies of Wadia, R.S. et al. (1987) [19] and Pazzaglia et al. (1981) [20] in which the patients below age of 20 years were $40 \%$ and $50 \%$ respectively.

Type of seizures: In this study, all patients presented with seizures. $48.57 \% \quad(n=34)$ patients presented as simple partial seizures with secondary generalization, $31.43 \%(\mathrm{n}=22)$ patients presented as generalized tonicclonic seizure, $17.14 \% \quad(n=12)$ presented as simple partial seizure without secondary generalization and only $2.86 \%(\mathrm{n}=2)$ patients presented as complex partial seizure which was similar to the study conducted by Kotokey, R.K.; Lynrah, K.G. and De, A. (2006) [21].
Site of beginning of seizure: The site of beginning of seizure in present study was upper limb in $71.43 \%$ $(n=50)$ followed by lower limb $18.57 \%(n=13)$, face $10 \%(n=7)$. Kumar et. al. [22] observed that in $59 \%$ of their patients, seizures began from upper limb or face.

Neurological examination: In present study, on neurological examination, $85.71 \%(n=60)$ were found to be normal, $11.43 \%(n=8)$ had focal neurological deficit. Out of which $10 \%(n=7)$ have monoparesis and $1.43 \%$ $(\mathrm{n}=1)$ have hemiparesis. Papilloedema was found in $2.86 \%(\mathrm{n}=2)$. In an another study conducted by $\mathrm{OH}$ Del Brutto et al. [23] $80 \%$ patients were normal by neurological examination, $16 \%$ patients had focal neurological deficit and $4 \%$ patients had papilloedema, which is similar to our study where monoparesis and hemiparesis were the most frequent neurological signs.

\section{Conclusion}

Our study revealed that epilepsy is most common clinical manifestation in neurocysticercosis in which simple partial seizure with secondary generalization is most common type of seizure presentation.

Neurocysticercosis is more common in young, rural population and in lower socioeconomic class. Vegetarians were significantly more affected than nonvegetarians which suggest other mode of transmission than meat eating.

By combining hygiene education and better sanitation, we will interrupt or reduce the cycle of direct person-toperson transmission. Thus, probably we will succeed to reduce the burden of disease in the society.

Funding: Nil, Conflict of interest: None initiated, Permission from IRB: Yes

\section{References}

1. White AC Jr. Neurocysticercosis: updates on epidemiology,pathogenesis, diagnosis and management. Annu Rev Med.2000;51:187-206.

2. White AC Jr. Neurocysticercosis: a major cause of neurological disease worldwide. Clin Infect Dis. 1997 Feb;24(2):101-13; quiz 114-5.

3. Recommendations of the International Task Force for Disease Eradication. MMWR Recomm Rep. 1993 Dec 31;42(RR-16):1-38. 
4. Garcia HH, Del Brutto OH; Cysticercosis Working Group in Peru. Neurocysticercosis: updated concepts about an old disease. Lancet Neurol. 2005 Oct; 4(10):653-61.

5. Garcia HH, Oilman RH. Cysticercosis In Oxford TextBook of Medicine 4th edition. Edited by Warrel DA, Cox TM, Firth JF. Oxford. Oxford University Press 2003; 824-829.

6. Santibanez SS, Steele RW, Mushat DM. Chronic headache in woman from Honduras. Infect Med 1999; 164:230-234.

7. Hawk MW, Shahlaie K, Kim KD, Theis JH. Neurocysticercosis: a review. Surg Neurol. 2005 Feb; 63(2):123-32; discussion 132.

8. Jha S, Kumar V. Neurocysticercosis presenting as stroke. Neurol India. 2000 Dec;48(4):391-4.

9. Garg RK, Karak B. Neurocysticercosis presenting as midbrain syndrome. J Assoc Physicians India. 2000 May;48(5):533-5.

10.Singh NN, Verma R, Pankaj BK, Misra S. Neurocysticercosis presenting as Weber's syndrome. Neurol India. 2003 Dec;51(4):551-2.

11. Agarwal V, Kumar P, Chadda RK. Neurocysticercosis presenting as psychiatric illness. Indian $\mathbf{J}$ Pediatr. 2001 Nov;68(11):1073-4.

12. Bourgeois JA, Motosue J, Mehra N. Mood and psychotic symptoms with neurocysticercosis. Psychosomatics. 2002 Jul-Aug;43(4):337-8.

13. Del Brutto OH, Rajshekhar V. White Ac J. et al. Proposed diagnostic criteria for neurocysticercosis. Neurology 2001; 57:177-83.

14. Guidelines for epidemiologic studies on epilepsy. Commission on Epidemiology and Prognosis, International League Against Epilepsy. Epilepsia. 1993 Jul-Aug;34(4):592-6.
15. Del Brutto OH, García E, Talámas O, Sotelo J. Sexrelated severity of inflammation in parenchymal brain cysticercosis. Arch Intern Med. 1988 Mar;148(3):544-6.

16. Banerjee P.S., Bhatia B.B. \& Pandit B.A. (1994). Sarcocystis suihominis infection in human beings in India. J. vet. Parasitol., 8 (1), 57-58.

17. Varma A, Gaur KJ. The clinical spectrum of neurocysticercosis in the Uttaranchal region. J Assoc Physicians India. 2002 Nov;50:1398-400.

18. Singh MK, Garg RK, Nath G, Verma DN, Misra S. Single small enhancing computed tomographic (CT) lesions in Indian patients with new-onset seizures. A prospective follow-up in 75 patients. Seizure. 2001 Dec;10(8):573-8.

19. Wadia RS, Makhale CN, Kelkar AV, Grant KB. Focal epilepsy in India with special reference to lesions showing ring or disc-like enhancement on contrast computed tomography. J Neurol Neurosurg Psychiatry. 1987 Oct;50(10):1298-301.

20. Pazzagalia B; V.Grinnel, M.A. Goldberg, and D.Heiner. 1981 : Spontaneous radiographic disappearance of cerebral cysticercosis. Neurology 33 : 1337-1357.

21. Kotokey RK, Lynrah KG, De A. A clinicoserological study of neurocysticercosis in patients with ring enhancing lesions in CT scan of brain. J Assoc Physicians India. 2006 May;54:366-70.

22. Kumar AS, Subrahmanyam DK. Neurocysticercosis presenting as pseudobulbar palsy. J Neurosci Rural Pract. 2014 Jan;5(1):76-7. doi: 10.4103/0976-3147. 127883.

23. Del Brutto OH, Sotelo J, Aguirre R, Díaz-Calderón E, Alarcón TA. Albendazole therapy for giant subarachnoid cysticerci. Arch Neurol. 1992 May;49(5):535-8.

\section{How to cite this article?}

Anoop Kumar, Singh R.R, Verma VK, Uraiya D, Tripathi N. Spectrum of epilepsy in Neurocysticercosis. Int J Med Res Rev 2016;4(8):1443-1447.doi:10.17511/ijmrr.2016.i08.27. 